\title{
Successful treatment by doxycycline of endocarditis caused by ornithosis
}

\author{
L J E WALKER, A A J ADGEY \\ From the Regional Medical Cardiology Centre, Royal Victoria Hospital, Belfast, Northern Ireland
}

SUMMARY The case of a 59 year old man with ornithosis endocarditis and a history of contace with pheasants is reported. Treatment with oxytetracycline was not tolerated and so doxycyclinel was substituted. Over the two year follow up the patient's clinical condition and serial echo $\vec{G}$ cardiographic appearances improved and Chlamydia psittaci complement fixation titres returne民্ㅇ to normal. Valve replacement was not required.

\section{Case report}

A 59 year old security officer was admitted to hospital in Londonderry, on 4 August 1983. He gave a six month history of loss of energy, anorexia, excessive sweating, non-productive cough, mild shortness of breath, and weight loss of $16 \mathrm{~kg}$. Early on in the illness, he had noticed headaches in the morning. There was no previous cardiac history. Medication on admission was oral iron. He had not received antibiotics.

He kept chickens, which appeared to be healthy. He had not been in contact with budgerigars, turkeys, pigeons, parakeets, or cats.

He was thin on admission, with a temperature of $100^{\circ} \mathrm{F}\left(37 \cdot 75^{\circ} \mathrm{C}\right)$. Early finger clubbing was present, but there were no petechiae or splinter haemorrhages. There was no lymphadenopathy. A grade $3 / 6$ apical systolic murmur radiating to the axilla and a grade $1 / 6$ early diastolic murmur along the left parasternal edge were heard. Chest was clinically clear. The spleen was enlarged (3 fingerbreadths) but the liver was not. Fundoscopy was normal.

The initial haemoglobin concentration $(10 \mathrm{~g} / \mathrm{dl})$ and red cell indices, and white cell, platelet and reticulocyte counts were normal. The erythrocyte sedimentation rate was $>150 \mathrm{~mm} / \mathrm{h}$. Blood urea and electrolyte concentrations and liver function tests were normal. Six blood cultures showed no growth. Gammaglobulin was $50 \mathrm{~g} / 1$ (normal range 7-15 g/l), C3 complement $0.42 \mathrm{~g} / 1$ (normal range $0.5-1.2 \mathrm{~g} / \mathrm{l}$ ),

Requests for reprints to Dr L J E Walker, Regional Medical Cardiology Centre, Royal Victoria Hospital, Belfast BT12 6BA, Northern Ireland. and C4 $0 \cdot 18 \mathrm{~g} / 1$ (normal range $0 \cdot 2-0.5 \mathrm{~g} / \mathrm{l}$ ). Circu lating immune complexes were not detected. Urine microscopy showed no red cells and a chest $x$ ray indicated slight cardiomegaly. Electrocardiogranep showed mild left ventricular hypertrophy on voltage criteria. Serological testing for $Q$ fever, Brucellog Mycoplasma pneumoniae, and the Paul-Bunnell reacs tion were negative. The Chlamydia psittaci com plement fixation titre was $1: 160$. $M$ mode echoő cardiography showed a vegetation on the mitra valve.

Culture negative endocarditis was diagnosed? Intravenous benzylpenicillin (16 megaunits) an gentamicin $(240 \mathrm{mg})$ given daily in divided dose. were started on the second day of admission. Afte产 this treatment the patient felt better and there was no fever. Splenomegaly diminished rapidly.

On the tenth day of admission the patient was़. transferred to our centre. Cross sectional echo 8 cardiography confirmed a vegetation on the mitra valve. There was moderate mitral and aortic income petence. The non-coronary cusp of the aortic valve which was tricuspid, appeared to be partially diso rupted.

After three weeks, penicillin treatment was with? drawn because severe neutropenia developed. ThS white cell count recovered rapidly after withdraw of the drug. Vancomycin was substituted and genब tamicin was continued. Six weeks after his initia admission to hospital the Chlamydia psittaci com plement fixation titre was 1:1280 and oxy? tetracycline $(250 \mathrm{mg}$ orally four times a day) was started. Vancomycin (which he had been given fo? three weeks) and gentamicin (for six weeks) were discontinued.

Further questioning at this stage revealed a new 
possible source of infection-his son's pheasants. The patient, who was responsible for feeding them, had noticed that two of them had been unwell and that they were "shedding feathers". Six months before admission he had injured the palm of his right hand on the barbed wire fence enclosing the pheasants. The pain caused by the injury was so severe that he was unable to use his hand for three days.

Because oxytetracycline caused nausea and vomiting in this patient we treated him with doxycycline (200 mg orally daily), which was well tolerated. Treatment was continued for two years, and during this time he gained weight, and the haemoglobin, erythrocyte sedimentation rate, and high $\gamma$ globulin concentration became normal. The Chlamydia psittaci complement fixation titre reverted to $1: 160$. Serial echocardiography (fig a and b) showed that the vegetation on the mitral valve became smaller. Moderate mitral and aortic incompetence persist.

Disposal of the birds by the patient's family was unsatisfactory; the chickens were sold and the pheasants were set free.

\section{Discussion}

Endocarditis caused by Chlamydia is rare. In a recent review of 544 episodes of infective endocarditis in 541 patients Bayliss et al reported nega- tive blood cultures in 53 cases. ${ }^{1}$ Chlamydia was only implicated in one case. In an earlier review by Pesanti and Smith of 52 cases of culture negative endocarditis, Chlamydia was not mentioned. ${ }^{2}$ We have found nine published reports of Chlamydia psittaci throughout the world. ${ }^{3-9}$ Of these six survived. Three of these owed their survival to valve replacement. $^{349}$ The only patient in whom medical treatment alone was successful was described by Jariwalla et al. ${ }^{7}$ In their patient tetracycline treatment failed but rifampicin was successful.

Most patients had been in contact with birdsbudgerigars, parrots, canaries, and pigeons seemed to be the main sources of infection. In 1967 Meyer reviewed the host range of Chlamydia and tabulated about 130 species of birds known to harbour Chlamydia. ${ }^{10}$ Other animals, including the domestic cat, can spread the disease. Regan et al reported infective endocarditis with glomerulonephritis associated with Chlamydia psittaci infection of a cat. ${ }^{11}$ In our patient the birds that appeared to have been infected were the pheasants. Nevertheless, apparently healthy chickens can harbour the organism. We could not confirm the source of infection, because all of the birds had been disposed of; unfortunately they were not destroyed as has been recommended. ${ }^{12}$

On at least three occasions our patient had been questioned closely about avian contact. The fact that
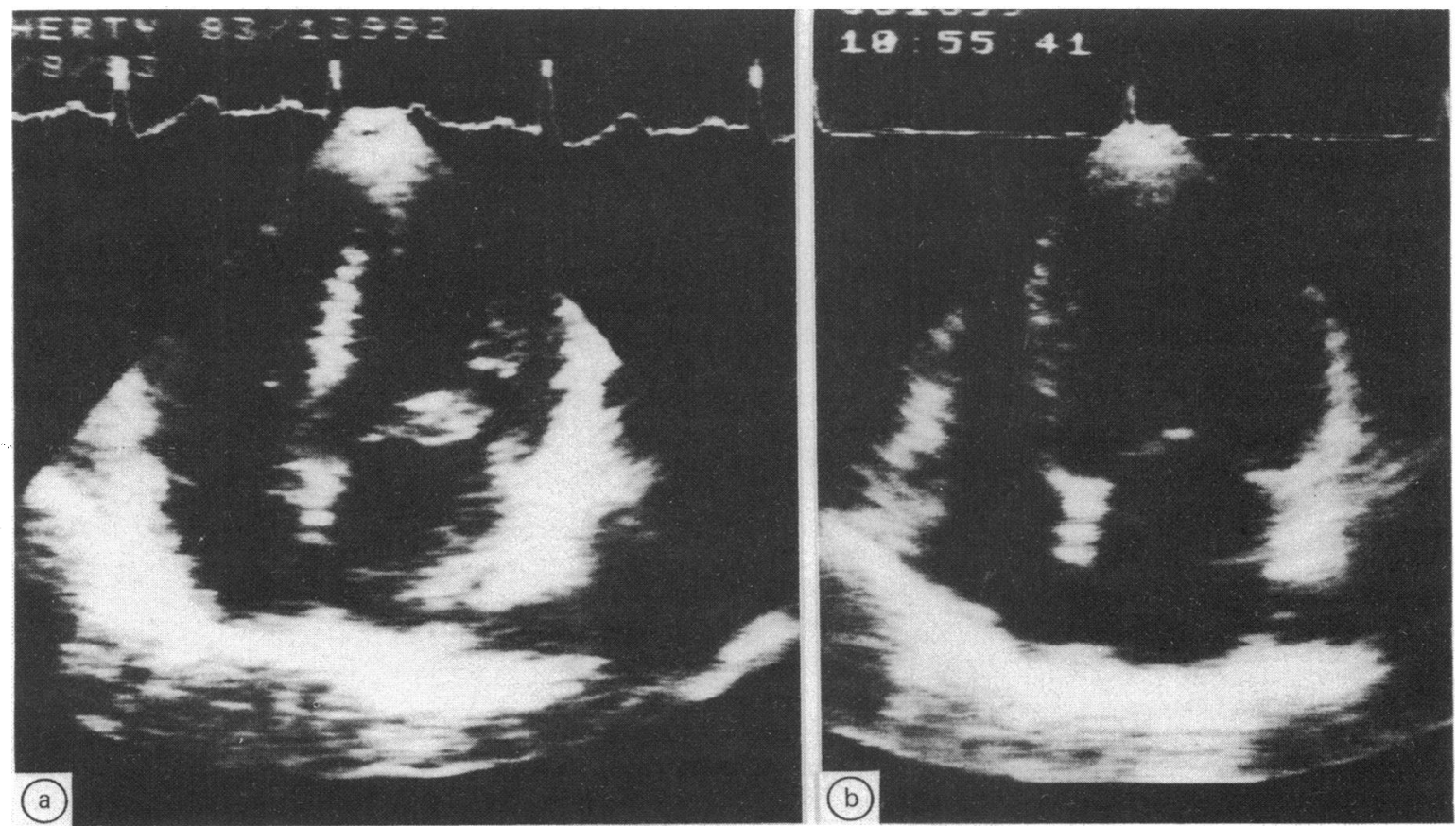

Figure Cross sectional echocardiograms of a four chamber view obtained in September 1983 (a) and showing a vegetation on the mitral valve and (b) in August 1985. The size of the vegetation on the mitral valve is considerably reduced in (b). 
the most relevant part of the history only emerged after repeated questioning is in keeping with the experience of others, who have found that a history of exposure to birds is often only obtained after repeated questioning.

This patient is unusual in that pneumonitis did not appear as a major complication, nor was it the reason for presentation. ${ }^{13}$ Cardiac complications of chlamydial infection include myocarditis, ${ }^{14}{ }^{15}$ pericarditis, ${ }^{16}$ and endocarditis. ${ }^{3-9}$ In addition, Ward and Ward have suggested a link between chronic infection and acquired valve disease. ${ }^{17}$ Embolic phenomena have been described, ${ }^{5}$ but were not a feature in this case.

The initial good response to benzylpenicillin and gentamicin treatment was undoubtedly due to the penicillin; however, many workers have observed penicillin treatment failures. The aminoglycosides have no demonstrable activity against the organism. ${ }^{10}$ There is another published report of successful medical treatment with doxycycline; however, the patient died a month after double valve replacement that was carried out approximately two years after the initial presentation. ${ }^{11}$ Because Chlamydia psittaci is an intracellular organism, ${ }^{16}$ and tetra-cycline is only a static agent the patient is being kept under close review in case the need for long term doxycycline treatment or valve replacement or both arises. Oakley has suggested that valve replacement should be carried out in most cases. ${ }^{18}$ After two years' follow up, the Chlamydia psittaci complement fixation titre in our patient remains at 1:160. Valve replacement has not been necessary.

\section{References}

1 Bayliss R, Clarke C, Oakley CM, Somerville W, Whitfield AGW, Young SEJ. The microbiology and pathogenesis of infective endocarditis. $\mathrm{Br}$ Heart $\mathcal{F}$
1983;50:513-9.

2 Pesanti EL, Smith IM. Infective endocarditis with negative blood cultures. An analysis of 52 cases. $A$ in: f Med 1979;66:43-50.

3 Ward C, Sagar HJ, Cooper D, Ward AM. Insidioug endocarditis caused by Chlamydia psittaci. $\mathrm{Br} \mathrm{Med} \Phi$ 1975;iv:734-5.

4 Birkhead JS, Apostolov K. Endocarditis caused by psittacosis agent. Br Heart $\mathcal{F}$ 1974;36:728-31.

5 Bromage D, Jeffries DJ, Philip G. Embolic phenomen in chlamydial infection. Fournal of Infection 1980 2:151-9.

6 Levison DA, Guthrie W, Ward C, Green DM $\overrightarrow{\vec{G}}$ Robertson PGC. Infective endocarditis as part of psittacosis. Lancet 1971:ii:844-7.

7 Jariwalla AG, Davies $\mathrm{BH}$, White J. Infective endór carditis complicating psittacosis: response to rifam ${ }^{2}$ picin. $\mathrm{Br}$ Med F 1980;280:155.

8 Grist NR, McLean C. Infections by organisms of Psittacosis/Lymphogranuloma venereum group in the West of Scotland. $\mathrm{Br} \mathrm{Med} \mathcal{F}$ 1964;ii:21-5.

9 Jones RB, Priest JB, Kuo CC. Subacute chlamydiat endocarditis. $\mathcal{F} A M A$ 1982;247:655-8.

10 Schachter J, Dawson CR. Psittacosis. In: Human chla mydial infections. Littleton, Massachusetts: PSG Publishing Company, 1978:9-43.

11 Regan RJ, Dathan JRE, Treharne JD. Infective endo carditis with glomerulonephritis associated with cat chlamydia (C psittaci) infection. $\mathrm{Br}$ Heart 1979;42:349-52.

12 Macfarlane JT, Macrae AD. Psittacosis. Br Med Bul历 1983;39:163-7.

13 Murray HW, Tuazon C. Psittacosis. Med Clin N Ang 1980;64:515-9.

14 Coll $\mathrm{R}$, Horner I. Cardiac involvement in psittacosis Br Med f 1967;4:35-6.

15 Dymock IW, Lawson JM, MacLennan WJ, Ross CAC Myocarditis associated with psittacosis. $\mathrm{Br} \mathcal{F}$ Clin Pract 1971;25:240-2.

16 Isaacs D. Psittacosis. Br Med f 1984;289:510-1.

17 Ward C, Ward AM. Acquired valvular heart-disease in patients who keep pet birds. Lancet 1974;ii:734-6.

18 Oakley CM. Infective endocarditis. $B r \mathcal{F}$ Hosp Med 1980;24:232-43. 